\title{
Los Autores
}

\section{Beethoven Herrera Valencia}

Economista, Doctor en Economía Internacional del Instituto de Estudios Políticos de París, Miembro de número de la Academia Colombiana de Economistas, Profesor Emérito de la Universidad Nacional de Colombia y actualmente Profesor de la Universidad Externado de Colombia. Tiene numerosas publicaciones sobre economía y finanzas, particularmente sobre Colombia y América Latina. Es columnista del área economía y finanzas en varios medios de comunicación. Ha sido premiado en numerables ocasiones por sus contribuciones en la investigación, formación de profesionales y ha sido Presidente de la Academia de Ciencias Económicas de Colombia.

LiLIa Quituisaca-SAMANiEgo

Máster: Analítica Visual y Big Data / Ingeniería Informática. Actualmente se desempeña en Sociedad Ecuatoriana de Estadística. Quito-Ecuador

\section{Carlos Almeida}

Máster en Ciencias de la Gestión (MBA), Universidad Católica de Lovaina (UCL), Louvain la Neuve - Bélgica. Post-doc, Universidad Técnica de Munich (TUM). Munich, Alemania. Actualmente es Profesor en el Departamento de Matemática de la Escuela Politécnica Nacional, Quito, Ecuador 


\section{LUIS ANTAMBA}

Ingeniero Matemático, Universidad Central del Ecuador. Docente en la Universidad de Las Américas, Ecuador y asesor financiero en Riesgos de crédito ICESA S.A. Quito - Ecuador

\section{ERICK Fuentes GóngORA}

Licenciado en Arte por la Pontificia Universidad Católica de Valparaíso. Magister en Arte mención Patrimonio por la Universidad de Playa Ancha y Consejero del Comité Nacional de Chile Memoria del Mundo (MOW Chile), United Nations Educational, Scientific and Cultural Organization (UNESCO). Líneas de investigación: patrimonio cultural; memoria y derechos humanos; 